\title{
The more things change
}

\author{
James I. Fann, MD
}

\author{
From the Department of Cardiothoracic Surgery, Stanford University, Stanford, Calif. \\ Disclosures: Author has nothing to disclose with regard to commercial support. \\ Received for publication March 27, 2017; accepted for publication March 28, 2017; available ahead of print April \\ 22, 2017. \\ Address for reprints: James I. Fann, MD, Department of Cardiothoracic Surgery, Stanford University, 300 Pasteur \\ Drive, Stanford, CA 94305 (E-mail: jfann@stanford.edu). \\ J Thorac Cardiovasc Surg 2017;154:87-8 \\ 0022-5223/\$0.00 \\ Published by Elsevier Inc. on behalf of The American Association for Thoracic Surgery \\ http://dx.doi.org/10.1016/j.jtcvs.2017.03.124
}

In 1970, Daily and colleagues ${ }^{1}$ simplified the classification of aortic dissection to type A as involving "the ascending aorta from dissection originating there or from a proximal dissection" and type B as "limited to the descending aorta." This reclassification was driven by their observation that there was a "tendency for type A dissection to rupture into the pericardium," thereby lending prognostic and therapeutic guidance. ${ }^{1}$ In reviewing their experience of 23 patients treated medically (with $67 \%$ mortality) or surgically (with $28 \%$ mortality) for type A dissection and incorporating the experience of others, Daily and colleagues ${ }^{1}$ concluded that patients with acute type A dissection are optimally treated with early surgery to prevent the development of life-threatening complications, such as rupture. Over the years, because of the emphasis on the incremental mortality with time in untreated patients with acute type A dissection ( $1 \%$ per hour for the first 24 hours), the timing of surgery is often cited as the main modifiable variable in improving outcomes. In a circular fashion, identified risk factors for operative mortality in these patients relate directly to complications of aortic dissection, including rupture and the presence of cerebral, coronary, renal, visceral, spinal cord, and limb malperfusion, the avoidance of which mandates consideration of early timing of surgery.

In this issue of the Journal, Narayan and colleagues ${ }^{2}$ first acknowledge the need for early operation in this patient population. Yet, in seeking greater granularity, they propose that the outcome is related less to timing of surgery and more to whether there is evidence of malperfusion. In making their case, they report that "timing merely acts as a surrogate marker with immediate operation preventing development of malperfusion and delayed operation selecting patients with minimal or no malperfusion." 2 To fully understand the ramifications of their precept, perhaps we need to revisit the findings and recommendations of Daily and colleagues ${ }^{1}$ approximately 5 decades ago.

In regard to study design, to provide for adequate comparison groups and based on total number and demographics of patients, Narayan and colleagues ${ }^{2}$ group the patients into those who underwent surgery within 12 hours of symptom onset and those who underwent surgery more

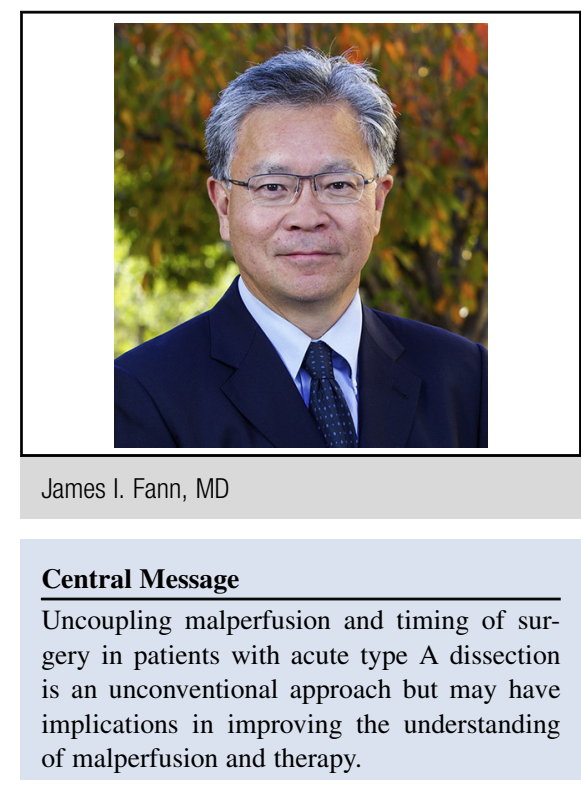

See Article page 81 .

than 12 hours after symptom onset, a categorization that is scientifically arbitrary but not unreasonable given the study constraints. The obvious deficiency of this approach harkens to the concept of self-selection in that those who had rupture before transfer did not make it into the study, thus possibly biasing the results toward later timing of surgery. Nonetheless, early mortality rates between the 2 groups are statistically similar; for early surgical intervention, the rate is $19.4 \%$ compared with $13.8 \%$ for later surgery. Consistent with previous studies, the presence of malperfusion is associated with increased risk of death in both the short and long term. Specifically regarding timing, Narayan and colleagues ${ }^{2}$ find that delayed operation is associated with a reduced risk, but this reduction is not significant when malperfusion was accounted for. That is, any variability in outcome can be explained by the onset and progression of malperfusion, leading the authors to report that the time-related outcome is "a function of time related changes in organ perfusion." 2

To a large extent, the fascination with aortic dissection has its roots in its pathophysiologic dynamism and the idea of self-selection in that patients may present in different stages of malperfusion, which in turn is associated with varying surgical risks. Consistent with the idea of malperfusion spectrum (no malperfusion, subclinical malperfusion, and marked malperfusion), it would seem that the treatment algorithm should incorporate information 
regarding where the patient is on this scale. But because of the dynamic and high-risk nature of aortic dissection, such an approach would require more data analytics, much of it predictive.

Over the years, the approach advocated for acute type A dissection is early timing of surgery. Because one cannot as yet determine the likelihood of developing malperfusion in the first 12 to 24 hours, the recommendation for early surgery is unlikely to change. The findings of Narayan and colleagues ${ }^{2}$ impel us to review the history of the development of the classification and treatment (or in fact vice versa) of acute type A dissection and to acknowledge that early timing of surgery in these high-risk patients was originally proposed to prevent malperfusion and to respond to the most catastrophic complications.
To avoid being dismissive and falling into the belief that "the more things change, the more they stay the same," 3 we need to remind ourselves of the origin and rationale of many of our treatments, so that we can re-ask the questions using modern investigational methods, as in this study, in developing appropriate therapeutic approaches. Now, the question is whether we can identify the cohort of patients who are at lower risk for the development of malperfusion and tailor their treatment.

\section{References}

1. Daily PO, Trueblood HW, Stinson EB, Wuerflein RD, Shumway NE. Management of acute aortic dissections. Ann Thorac Surg. 1970;10:237-47.

2. Narayan P, Rogers CA, Benedetto U, Caputo M, Angelini GD, Bryan AJ. Malperfusion rather than merely timing of operative repair determines early and late outcomes in type A aortic dissection. J Thorac Cardiovasc Surg. 2017;154:81-6.

3. Jean-Baptiste Alphonse Karr. Available at: https://en.wikipedia.org/wiki/JeanBaptiste_Alphonse_Karr. Accessed March 25, 2017. 